\title{
Human resource development formulation and evaluation in an Iranian Petrochemical Company using ANP and grey relational analysis
}

\author{
Ahmad Reza Ghasemi ${ }^{a^{*}}$, Sasan Beigilanlouei ${ }^{\mathrm{b}}$ and Hosein Pourmahdian
}

${ }^{a}$ Assistant professor, Department of Management and Accounting, Farabi Campus, University of Tehran, Iran

${ }^{b}$ Ms Student in Industrial Management, Department of Management and Accounting, Farabi Campus, University of Tehran, Iran ${ }^{c} M S c$. in Applied Mathematics, Mathematic Department, Amirkabir University, Tehran, Iran

C H R O N I C L E

Article history:

Received January 5, 2016

Received in revised format April

15,2016

Accepted June 2, 2016

Available online

June 7, 2016

Keywords:

Human resource development

strategy

SWOT analysis

Analytical Network Process

(ANP)

Grey Relational Analysis (GRA)

Abadan Petrochemical Company

\section{A B S T R A C T}

\begin{abstract}
Today, human capital is considered a key factor of achieving the competitive advantage in different industries. The present study, as an applied and descriptive research, aims at providing formulation and evaluation of human resource development of an Iranian Petrochemical Company (APC). The human resource experts and managers of APC together with university professors of human capital and familiar with local conditions of Khuzestan province, Iran, made up the statistical population of this research. In this connection, first the internal factors (including advantages and disadvantages) were identified using human resource excellence indicators. Then, the opportunities and threats of human resource system were found via PESTEL approach. In the next step, the primary strategies were formulated using the strength, weakness, opportunities and threats (SWOT) Matrix. The next phases of the study were included evaluation and ranking of human resource development strategies based on analytical network process (ANP) multi-criteria decision making method and grey systems theory. According to results of the research, defensive strategies (WT) are suggested as the best and most appropriate strategies in human resource area. In other words, the internal and external factors of APC are problematic. Accordingly, APC is expected to adopt WT strategy, minimize the weaknesses, and avoid threats. Subsequent to the above policy, the strategies of WO, ST, and SO are advised to employ.
\end{abstract}

\section{Introduction}

Paying attention to human resource development in order to equip and empower the managers and staff, as the most valuable asset of organizations, has been taken seriously into consideration over the recent decade. Therefore, it is counted today key to world-class learning organizations and the currently available ones and this issue indicates that in a knowledge-based global approach, individuals are considered as strategic and determinant resources within organizations and life of which the empowerment would result in a political, social and economic sustainable development. Irrespective

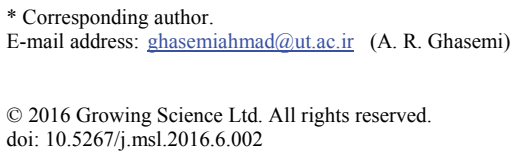


of its importance and key role, human capital is still counted as an intangible asset. The related expense of the aforementioned department is so much high that, given its achievements and advantages for organizations, the human resource unit, as experts believe, is expected to play more serious role in determining the strategies and organizing the staff. This unit needs to be developed more in line with the overall strategies of organizations (Tyson, 1987). Numerous approaches and techniques are used in strategic management process (Dincer, 2004) among which SWOT analysis is the most common (Hill \& Westbrook, 1997). SWOT analysis is an important support in decision making and is used usually as a tool for a systematic analysis of internal and external factor evaluations (IFE and EFE) (Stewart, et al. 2002). In order to detect the internal factors (strengths and weaknesses) and external factors (opportunities and threats) of APC, the present study used human resource excellence indicators and PESTEL approach, respectively. Then, the primary strategies were developed by SWOT matrix, followed by evaluation and ranking of strategies based on Analytical Network Process (ANP) and Grey Relational Analysis (GRA). The next parts of the research include literature, methodology, and analysis of findings, results and suggestions.

\section{Research literature and theoretical framework}

\subsection{Strategic management of human resource}

Strategic management of human resource, set forth in early 1980s within the American management literature, was developed to access active human resource managers in functional role-based strategies of this type of management on open weaknesses and environmental pressures. The strategic essence of human resource reveals the significance of human resource management for the overall strategy of organizations and different environmental challenges against human resource management based on which organizations were required to consider in 1980s. Scholars still seek for a powerful theory for human resource strategic management (Delery \& Shaw, 2001). Former studies have been dealt first with evaluation of existing relationship between the organizational strategies of human resource strategic management, such as policies, measures and human resource management systems, and organizational efficiency (Chadwick, 1999). However, lack of a theoretical framework to make the abovementioned primary connections understandable has caused many academic criticisms and controversies on researches about human resource strategic management up to the present time. A number of experts believe in this connection that they do not understand a process in which human resource strategic management determines values and strengthens the efficiency of the organization (Wright \& McMahan, 1999). Some theoretical studies have shown that a theoretical framework for human resource strategic management is expected to encompass attitudes of multiple owners of capital (Ferris, 1998). Some other experts maintain that setting forth of a theoretical framework for human resource strategic management is not possible unless the efficiency of the organization is made clear precisely. Authors and experts of human resource management have found out that the efficiency management of human resource is able to determine the quality of the product and provide competitive advantage when considers these strategically. Strategic attitude to human resource management is caused by the increasing importance of its role in production. Human resource strategic management associates with strategic decision makings of the organization on its human resources. This is a general plan to achieve goals via staff in which human resource management and strategic management are in connection with employees so that the strategic running of the organization is realized. Human resource strategic management aims at setting the organizational stage for future trends on staff management in terms of human resource long-term planning through its consistency with macro plans of the organization (Wright \& McMahan, 1992).

\subsection{SWOT Analysis}

SWOT analysis is an appropriate tool that analyzes all factors in an organization in different conditions in order to provide acceptable strategies. SWOT stands for strengths and weaknesses (IFE) and 
opportunities and threats (EFE). This approach is developed based on the Harvard's attitude under the prescription paradigm. In this model, opportunities and threats are indicatives of main positive or negative challenges which are against the organization in the relevant industry, while strengths and weaknesses (competencies, abilities, skills and shortcomings) unveil the internal circumstances. SWOT matrix consists normally of a two-dimensional coordinate table of which each area represents a category of strategies that are demonstrated in Table 1.

\section{Table 1}

SWOT Matrix (Bamberger \& Meshoulam, 2002)

\begin{tabular}{ccc}
\hline EFE & IFE & \\
\hline Opportunities & strategies SO & strategies WO \\
Threats & strategies ST & strategies WT \\
\hline
\end{tabular}

\subsection{Analytical Network Process (ANP)}

In early studies, Analytical Hierarchy Process (AHP) was used as a multi-criteria decision making technique to solve complex decision makings. Saaty (1980) introduced AHP for the first time and used it for complicated problem solving. The main hypothesis of the AHP revolves around the independence of higher levels compared to lowers and the standards and other factors in each level. Many decision making issues cannot be structured hierarchically. AHP could be used when there is not any relationship between choices and standards, and analytical network process (ANP) may be used when alternatives and indicators are depended on each other (Saaty, 2006). The relationships in AHP are unidirectional hierarchies, while the relationships between indicators and decision making levels in ANP are bilateral. Accordingly, hierarchical structure with a downward linear relation is not suitable for a complicated system.

\subsection{Grey relational analysis (GRA)}

Grey Systems Theory (Julong, 1989) may contribute result evaluation of cases with incomplete and uncertain information ( $\mathrm{Li}$, et al., 2007). The studied fields by grey systems theory include system analysis, data processing, modeling, forecasting, decision making, and control (Hsu \& Wen, 2000). In order to introduce certain fundamental dimensions of GRA, first some general signs and operations are recommended, where $\mathrm{X}$ is a limited and closed set of real numbers. 1 is a grey number, $\otimes \mathrm{X}$ is a distance from upper and lower limits, however, distribution of unknown information for $\mathrm{X}$ is defined (Deng, 1989), i.e.:

$$
\otimes X=[\underline{\otimes} X, \bar{\otimes} X]=\left[\left(X^{\prime} \varepsilon X \mid \underline{\otimes} X \leq X^{\prime} \leq \bar{\otimes} X\right)\right]
$$

where $\bar{\otimes} \mathrm{X}$ and $\otimes \mathrm{X}$ are upper and lower limits of $\otimes \mathrm{X}$, respectively; in other words:

$$
\underline{\otimes} X_{i j}^{k}=\left[\underline{\otimes} X_{i j}^{k}, \bar{\otimes} X_{i j}^{k}\right]
$$

We define $\otimes X_{\mathrm{ij}}^{\mathrm{k}}$ as a grey number for $k$ expert that evaluates opinion of a human resource expert in a human resource development plan of $\mathrm{j}$. The grey relational analysis would be like a) grey relational analysis algorithm, b) normalization of values, c) grey relation coefficient, and d) grey relation advantage.

\subsubsection{GRA \& ANP-based model}

ANP method does not need a complicated mathematical modeling and calculation; it, however, provides a more powerful solution compared to simple scoring methods. In order to use ANP mode 
widely, the grey systems theory is merged in this study to make incorporation of incomplete and uncertain information possible. The merger of grey systems theory and ANP produces a powerful and convenient modeling tool for evaluation of human resource development of APC. This approach comprises 10 main steps, including:

1) Arrangement of a decision making network;

2) Provide pairwise comparisons;

3) Calculate the relative importance of factors (values) and their weight determination;

4) Weight calculation of interdependence of main factors;

5) Set decision making matrix;

6) Normalize the decision making matrix;

7) Calculate reference matrix;

8) Calculate Minkowski distance;

9) Calculate grey relative coefficient;

10) Calculate grey relation advantage.

\section{$2.5 \quad$ Research literature}

In order to confront the constructive competitions onrush, organizations need to be accountable and flexible. The human factor, if managed effectively, may play the most important role in organizational strategy. Management of human factor is included in human resource strategic management scope when it is counted as a competitive tool. People who work in organizations are considered as basic sources for performance of other resources. Therefore, based on an efficient human resource management, they could be considered a strategic asset. Organizations need to adapt themselves more to strategic resources in order to manage the staff. By adopting the strategic approach, they can count on staff as strategic resources to achieve competitive advantages (Abaspour, 2009).

Human resource strategic management has used widely in developed countries over the recent years in a way that, based on carried out studies, more than half of these countries have achieved new capabilities in their human resource strategic management by benefiting from obtained results of formulating human resource strategies (Abtahi \& Mousavi, 2009). The main long-term profit making factor for companies is employing a more appropriate and clear strategy than other rivals and also efficient staff who make their best to realize this strategy (Stewart \& Brown, 2010); this depends itself upon effective arrangement and implementation of usage of human resources. Thus, managers in the present time are expected to, by following strategic and systematic thinking, design, formulate, and implement intricate strategies and protect and support the intellectual capital as intangible asset which is capabilities and competencies of human resource (Abaspour, 2009).

In considering realism, rationality and comprehensiveness for development of human resource strategy, it is wise to move toward rising approaches (Bamberger \& Meshoulam, 2000) which refers attentions to intra organizational diagnosis and external factors. Kurttila et al. (2000) used a combined method for removing weaknesses of measurement and evaluation steps of SWOT analysis (Hill \& Westbrook, 1997). Yuksel and Dagdevirien (2007) used SWOT matrix and ANP for developing textile industry strategies. Momeni et al. (2009) used SWOT matrix and ANP for developing organizational strategies in a medical supplies manufacturing company. A study titled "formulation and evaluation of organizational strategies by SWOT and ANP models" maintains that in order to quantitative analysis of SWOT and examination of interdependencies between factors, the ANP method is used. The present research has made attempts to prioritize the organizational strategies for implementation. The hypothesis of interdependency between strategic factors would affect strategy adoption and priorities; and finally, SO strategy, with the highest significance, would be the most appropriate strategy for 
implementation (Momeni et al., 2012). The results of a study by Rostami and Jazani (2011) revealed that from among the effective factors on strategic empowerment, the strategic factor puts the highest impact on the staff empowerment, followed by structural factor as the next important element, and finally, individual dimension is the least effective factor on the staff empowerment. A research elaborated on human resource position in oil industry, and discussed its strengths and weaknesses by content analysis method, and ultimately, presented a human resource development model in line with 2025 outlook (Rayej et al., 2009). A study titled "Formulation of human resource strategies" was carried out in an Iranian spiritual organization aiming at developing appropriate strategies for human resource. The results of this research advised that the organization under study must use offensive and defensive strategies respectively for human resource input process, and human resource retain and output processes. The findings of the study unveiled that the organization under study, via successful implementation of the proposed strategies, can bring about synergic activities and coordination between human resource policies and overall strategies (Abtahi \& Mousavi 2009). "Formulation of human resource development strategies" is a research by Jazani performed on human resource management strategies. Covering opinions of experts on human resource development, the author has dealt with the implementation phases of human resource development system in organizations (Jazani, 2003).

Results of a study presented in the "Fourth International Management Conference" on elaboration of integrated human resources strategy indicated that Bahman Motor Company believes preserving of qualified and creative staff as its survival and success in business, and has set its strategies in line with protect and increase of credibility of this valuable asset. The present study makes attempt to show how human resource subsystem plays its direct or indirect role, as a human resource strategy, in realization of the organizational strategy via recruitment and selection of eligible persons, performance management development, determining an appropriate reward system, redefinition of business relations for each required profession. A research by Sayadi and Mohammadi (2009) has investigated the different theoretical approaches to human resource strategy (strategic and nonstrategic). The results of another study by Farahi (2006) titled "Strategic alignment of human resources and overall strategy and its effect on performance of organizations" revealed that, based on current theories in human resource strategic management such as contingency theory and behavioral perspective, those organizations who set their human resource strategies consistent with their competitive strategies are able to create a type of behavior and attitude in their staff that ease implementation of strategies, make them more effective, and consequently, contribute the organization to reach improved performance and promote its competitive position. A study by Buller and Mcevoy (2012) on human resource strategic management and investigation of the relationship between company's strategies and resources and its performance has unveiled the importance of human resource as a competitive advantage and the necessity of supporting the factor. In another entitled "Challenges and strategies of global human resource managers: views of Canada and the United States", the scholars, after going over some challenges of human resource managers of Canada and the United States, proposed solutions to treat the problems including diversity in employment, making changes in labor rules and regulations, cultural train and improvement, and leadership development (Ananthram \& Chang, 2013).

\section{Research methodology}

This is a case study and a descriptive and applied research in terms of data gathering and purpose, respectively. Qualitative and quantitative research methods were used in the current study to answer its main question. The case of this study was Abadan Petrochemical Company (APC). Due to the small size of human resource managers and staff, 8 of human resource experts of APC were determined as the statistical population of the research. All collected data was made by consensus of the experts. In order to investigate the validity of the questionnaires, the content and structure validity (consistent with theoretical discussions of strategic management in David's SWOT model) were used. The content validity of the questionnaires has been determined by academic and executive experts in the field under question. In order to assess the reliability of the questionnaires, Cronbach's Alpha coefficient was used, 
and the relevant calculations were performed by SPSS software. According to the results obtained, Cronbach's Alpha coefficient for EFE and IFE were calculated as 0.914 and 0.83, respectively which both values are greater than 0.7 . These coefficients, accordingly, prove the reliability of the assessment tool.

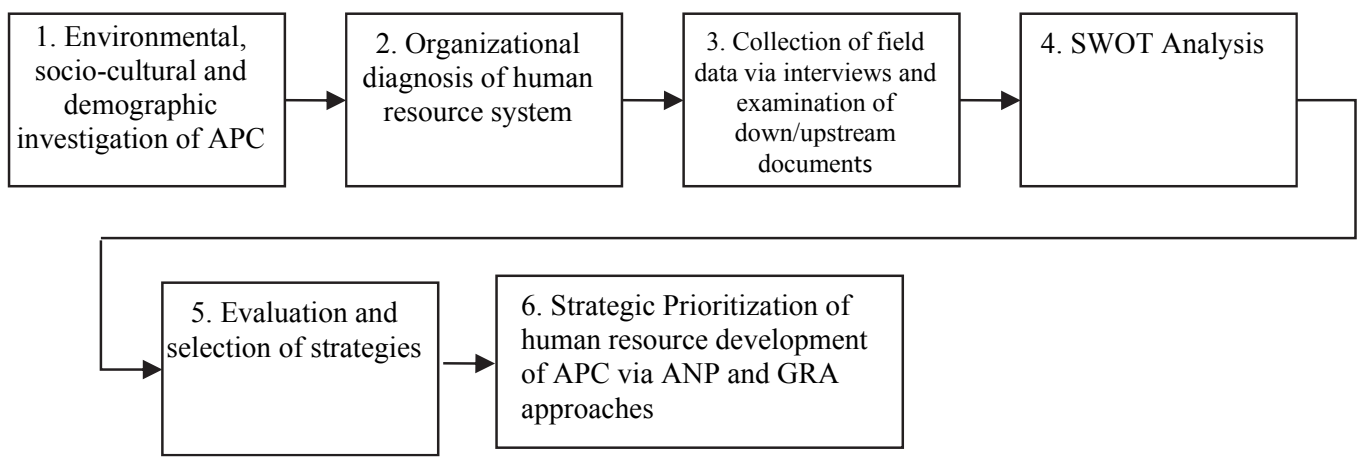

Fig. 1 Steps of human resource development investigation in APC

On EFE and IFE analyses, first, minor controllable and uncontrollable factors that were effective upon the success of the organization were identified. These factors are of strategic importance, and in order to determine the proposed strategies, SWOT Analysis was employed to reach the most appropriate strategies for the organization. The prioritization of the proposed strategies was made using ANP and GRA methods based on the model of Yuksel and Dagdeviren (2007). Different phases of data analysis are demonstrated in Fig. 1.

\subsection{Research findings}

\subsubsection{Human resource EFE of APC}

This study, using PESTEL analysis, deals with investigation of political, economic, socio-cultural, environmental and legal factors of external elements of organization. For this purpose, a semistructured questionnaire based on EFE and concerns was used. In order to get more familiar with views of experts of the company, certain sections were added to the questionnaire to provide experts' views on human resource environment.

To prepare a matrix evaluation of external factors, the following three steps were taken:

Step 1. Following examination of the known factors, 10 to 20 factors which cover important factors and cause opportunities or threats are listed.

Step 2. The efficiency of external effective factors with ratio statistical test is evaluated. The ratio nonparametric test was used because of the small size of the statistical samples.

Step 3. According to decision making rules, when the significance is smaller than 0.05 , the null hypothesis is rejected. Since SPSS tests only the postulate of $\mathrm{P}=\mathrm{P}_{0}$, to evaluate the efficiency of the desired variable, in addition to significance coefficient, the success ratio for statistic of $\bar{P}$ was considered as well. Table 2 shows the evaluated external factors and results of the ratio test.

$$
\left\{\begin{array}{l}
H_{0}: \mathrm{P}=\mathrm{P}_{0} \\
H_{1}: \mathrm{P} \neq \mathrm{P}_{0}
\end{array}\right.
$$

Given the 5-degree Likert scale in the questionnaire, in order to perform the ratio test, the mentioned scale was cut in two degrees of 3 (low efficiency) and 3+ (efficient). Also. The research postulate of $\mathrm{P}=0.5$ (as the null hypothesis) was considered. Given the significance level and the success ration of statistics, all factors are of high importance in table 2 . The underlying factors variable, meanwhile, is 
of moderate importance. Embracing the latest technology and equipment (automation, ergonomics, etc.) in APC in human resource-related areas

\section{Table 2}

Human source opportunities list

\begin{tabular}{|c|c|c|c|c|}
\hline No. & Factor & $(\bar{P})$ Observed ratio & Significance & Impact \\
\hline 1. & Positive attitude of job seekers and graduates of the province to work in APC & 0.88 & 0.07 & Positive \\
\hline 2. & Impact of honorable name of APC on employment of people out of the industry & 0.88 & 0.07 & Positive \\
\hline 3. & Young age of applicants in the province & 0.63 & 0.727 & Positive \\
\hline 4. & Increase of unemployment rate and availability of workforce in the labor market & 0.63 & 0.727 & Positive \\
\hline 5. & Strong brand of APC and its positive effect on winning attention of job applicants & 0.5 & 1 & \\
\hline 6. & Respectful behavior of APC managers and its positive effect on APC recruitments & 0.38 & 0.727 & \\
\hline 7. & Attractive job opportunity of APC as a free zone area & 0.38 & 0.727 & \\
\hline 8. & High rate of educated people in Abadan compared to the nationwide average rate & 0.5 & 1 & \\
\hline 9. & Positive attitude in APC to safety, health and welfare of employees & 0.25 & 0.727 & \\
\hline 10. & $\begin{array}{l}\text { Embracing the latest technology and equipment (automation, ergonomics, etc.) in } \\
\text { APC in human resource-related areas }\end{array}$ & 0.38 & 0.727 & \\
\hline
\end{tabular}

A quick overview to external opportunities of human resource system reveals that the most important factors in this area are caused by socio-cultural elements. This could be itself an indicative of importance of socio-cultural factors in human resource management.

Table 3

External threats list

\begin{tabular}{rlcc}
\hline No. & Factor & $(\bar{P})$ Observed ratio significance & impact \\
\hline 1. & $\begin{array}{l}\text { High expectations of staff from society, organization, and profession given the costs of } \\
\text { living }\end{array}$ & 0.88 & 0.07 \\
2. & $\begin{array}{l}\text { Changing economic conditions of the country and its negative effects on planning of } \\
\text { human resource in APC }\end{array}$ & 0.88 & 0.07 \\
3. & Inexperienced university graduates and difficult access to experienced workforce & 0.63 & 0.727 \\
4. & Impact of inflation rate on the performance of APC (increase of payments, costs, etc.) & 0.63 & 0.727 \\
5. & Favoritism in APC recruitments & 0.63 & 0.727 \\
6. & Increasing the education level of staff causing their welfare expectations to rise & 0.5 & 1 \\
7. & Negative attitudes to high rate of poverty in Abadan and the suburbs and its effects on & 0.5 & 1 \\
8. & APC recruitments & Degree-oriented approaches in the company instead of expertise & 0.38 \\
9. & Changing employment rules in different periods & 0.727 & 0.38 \\
10. & Negative attitudes in APC to less screening causing lack of inefficient workforce layoff & 0.38 & 0.727 \\
\hline
\end{tabular}

As discussed in earlier paragraphs on threats, 5 cases have been identified as effective factors among which economic factors are the most important followed by socio-cultural elements as the next significant external threats.

\subsubsection{IFE identification in APC}

Noe, the internal factors of the organization are evaluated here. The Internal Factor Evaluation (IFE) matrix is resulted from the strategic investigation of internal factors of the organization. Numerous indicators have been introduced for evaluation of weaknesses and strengths of human resource systems. The human resources excellence model was used in this connection in the present study. This adoption is because of reliance of this model on theoretical logic of excellence models and their exhaustive and integrated attitudes to performance evaluation. Irrespective of the common attitudes and given the limited statistical population and other considerations for this study, the self-reported questionnaire was used for assessment of excellence in human resources. For this purpose, the above questionnaire was distributed among the experts of the company of which the results are indicated in table 4 . The difference of this part with the previous one is that each variable upper than average is counted as strength here, the average indicators are excluded in analysis, and the ratios of lower than 50\% agreement are considered as weaknesses. Also for ease of analysis, instead of dealing with guide points, sub-indicators are analyzed. 
Table 4

Evaluation of strengths and weaknesses of the organization

\begin{tabular}{|c|c|c|c|c|}
\hline No. & sub-indicators & $(\bar{P})$ Observed ratio & significance & effect \\
\hline 1. & Human resource leadership & 0.71 & 0.453 & + \\
\hline 2. & strategies & 0.5 & 0.016 & \\
\hline 3. & Human resource organization & 0.5 & 0.016 & \\
\hline 4. & Human resource planning & 0.5 & 0.016 & \\
\hline 5. & Recruitment & 0.29 & 0.453 & . \\
\hline 6. & Human resource development & 0.14 & 0.125 & - \\
\hline 7. & Performance management & 0.29 & 0.453 & - \\
\hline 8. & Compensation and benefits & 0.5 & 0.016 & \\
\hline 9. & Relationship between profession and & 0.5 & 0.016 & \\
\hline 10. & Health and safety & 0.5 & 0.016 & \\
\hline 11. & Human resource perceptual results & 0.14 & 0.125 & _ \\
\hline 12. & Human resource performance results & 0.14 & 0.125 & - \\
\hline 13. & Organizational results & 0.14 & 0.125 & - \\
\hline
\end{tabular}

Based on the outputs of the above table, it is only the indicator of Human resource leadership which is in an acceptable level and is considered strength for the organization. Six items such as recruitment, human resource development, performance management, human resource perceptual results, human resource performance results and organizational results are in inappropriate levels and counted as weaknesses for the organization. Also six other indicators were seen at average.

\subsubsection{Formulation of human resource system strategies}

Following determination of internal and external factors effective on the human resource development of the organization, the appropriate strategies related to human resource management were set using SWOT matrix which are as follow:

\section{A. Human resource SO strategies (strengths and opportunities)}

By implementation of this strategy, the organization makes attempts to benefit from external opportunities via internal strengths.

\section{Table 5}

Human resource SO strategies

\begin{tabular}{|c|c|c|c|}
\hline No. & Strategy & Opportunities $(\mathrm{O})$ & Strengths (S) \\
\hline 1 & $\begin{array}{l}\text { Attendance of the manager in ceremonies to } \\
\text { appreciation the staff and welcome the newcomers }\end{array}$ & & $\begin{array}{l}\text { Human resource } \\
\text { leadership }\end{array}$ \\
\hline
\end{tabular}

\section{B. Human resource ST strategies (strengths and threats)}

By implementation of this strategy, the organization makes attempts to decrease or remove external threats via internal strengths.

Table 6

Human resource ST strategies

\begin{tabular}{clcc}
\hline No. & \multicolumn{1}{c}{ Strategy } & threats (T) & Strengths (S) \\
\hline 1 & $\begin{array}{l}\text { Leaders and managers of the organization makes attempts to win } \\
\text { participation and support of the staff in planning and new needs- }\end{array}$ & leadership \\
\hline
\end{tabular}

\section{Human resource WO strategies (weaknesses and opportunities)}

By implementation of this strategy, the organization makes attempts to cover its human resource weaknesses via benefiting from opportunities. 
Table 7

Human resource WO strategies

\begin{tabular}{|c|c|c|c|}
\hline No. & Strategy & Opportunities $(\mathrm{O})$ & Weaknesses (W) \\
\hline 1 & $\begin{array}{c}\text { Approve and use of scientific principles of recruitment during } \\
\text { employment process }\end{array}$ & & recruitment \\
\hline 2 & $\begin{array}{l}\text { Employ young, educated and motivated workforce in order to } \\
\text { reduce costs of the organization }\end{array}$ & & recruitment \\
\hline
\end{tabular}

\section{Human resource WT strategies (weaknesses and threats)}

By implementation of this strategy, the organization makes attempts to reduce its weaknesses and avoid human resource external threats.

\section{Table 8}

Human resource WT strategies

\begin{tabular}{|c|c|c|c|}
\hline No. & Strategy & Threats $(\mathrm{T})$ & Weaknesses (W) \\
\hline 1 & $\begin{array}{l}\text { More offer of welfare services to encourage the staff and cover shortage of } \\
\text { cash payments }\end{array}$ & & $\begin{array}{l}\text { Organizational } \\
\text { results }\end{array}$ \\
\hline 2 & $\begin{array}{l}\text { Compensate and cover restrictions caused by coordinated salary system via } \\
\text { approval of especial rules }\end{array}$ & & $\begin{array}{l}\text { Organizational } \\
\text { results }\end{array}$ \\
\hline 3 & $\begin{array}{l}\text { Empowerment of young staff with higher education and improvement of their } \\
\text { efficiency via running certain programs such as experience record, training } \\
\text { courses, etc. }\end{array}$ & & $\begin{array}{l}\text { human resource } \\
\text { development }\end{array}$ \\
\hline 4 & $\begin{array}{l}\text { Development of an educational system in line with needs of the managers and } \\
\text { employees based on training needs assessment }\end{array}$ & & $\begin{array}{l}\text { Human resource } \\
\text { performance results }\end{array}$ \\
\hline 5 & $\begin{array}{l}\text { Arrange and execution of required mechanism for implementation of } \\
\text { appropriate educational programs immediately after employment }\end{array}$ & & $\begin{array}{c}\text { human resource } \\
\text { development }\end{array}$ \\
\hline 6 & $\begin{array}{l}\text { Necessity of a fair compensation and reward system based on performance } \\
\text { and merits of employees in line with just organizational classifications. }\end{array}$ & & Perceptual results \\
\hline 7 & $\begin{array}{l}\text { Establish, promote and strengthen the system of meritocracy in the } \\
\text { appointment of staff based on their capability and competency }\end{array}$ & & recruitment \\
\hline
\end{tabular}

\subsubsection{Prioritization of human resources proposed strategies}

Following presentation of appropriate human resource strategies in APC, the next step includes prioritization of strategies using ANP and GRA methods. The usage phases of this model are made based on the proposed algorithm of Yuksel and Dagdeviren (2007). To calculate the final weights of alternatives in this model, super matrix is used. For this purpose, in addition to the above method, it is possible to use matrix operations as well. The latter is useful especially when there are low factors with internal relations (Yuksel \& Dagdeviren, 2007).

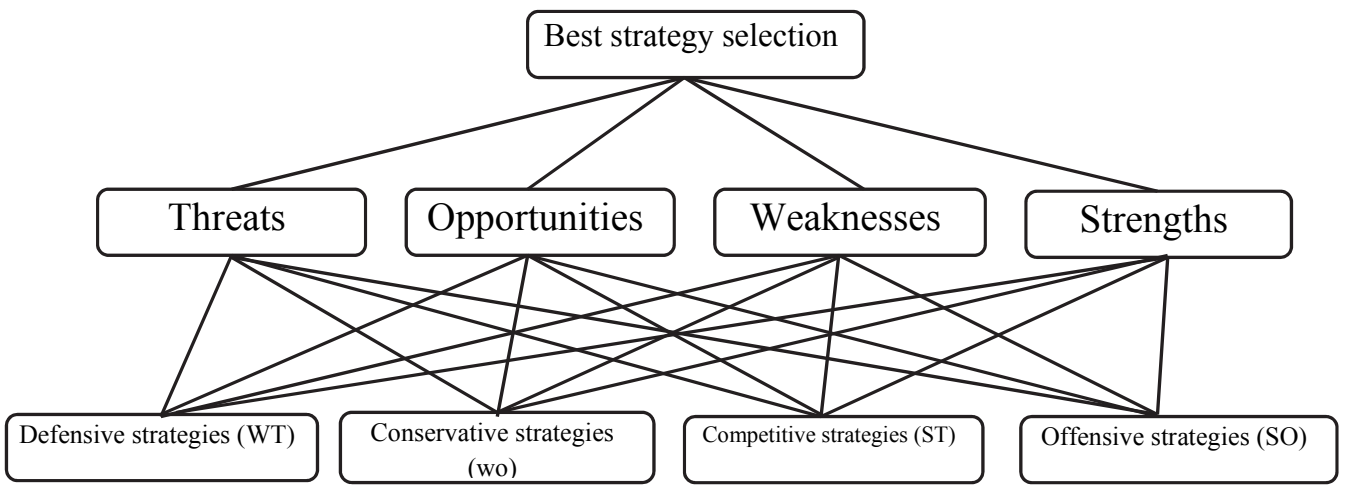

Fig. 2. General structure of decision making problem 
In matrix method, the details of the process are determined as well. The matrix method was employed in the present study since there were little internal relations, observable only between SWOT main factors. The problem is organized first as an ANP model with three levels; the first level is related to selection of the best strategy; the second one is associated with main factors of SWOT analysis; and the last level is about the problem choices and the strategies desired to this research. The model is demonstrated in Fig. 2. First, for weighing the indicators, ANP method was used. With assumption of zero interdependency between main factors of SWOT, the pairwise comparison matrix for the main factors was created by experts using 1-9 degree scale. This matrix was examined and weight vector was obtained.

\section{Table 9}

Pairwise comparison matrix of main factors and relative weight of each factor

\begin{tabular}{cccccc}
\hline & $\mathrm{T}$ & $\mathrm{O}$ & $\mathrm{W}$ & $\mathrm{S}$ & Relative weight \\
\hline $\mathrm{S}$ & $\frac{1}{2}$ & 2 & $\frac{1}{3}$ & 1 & 0.183 \\
$\mathrm{~W}$ & 3 & 2 & 1 & 3 & 0.45 \\
$\mathrm{O}$ & 1 & 1 & $\frac{1}{2}$ & $\frac{1}{2}$ & 0.164 \\
$\mathrm{~T}$ & 1 & 1 & $\frac{1}{3}$ & 2 & 0.203
\end{tabular}

$\mathrm{CR}=0.086$

Then, the interdependencies between the main factors are determined via investigation of the effect of each factor on other factors using the pairwise comparison matrices. The interdependencies between the main factors are obtained after internal and external analyses and are indicated in Fig. 3. Since opportunities are affected only by strengths, no pairwise comparison matrix is created for opportunities. The interdependencies between the main factors are shown in Fig. 3.

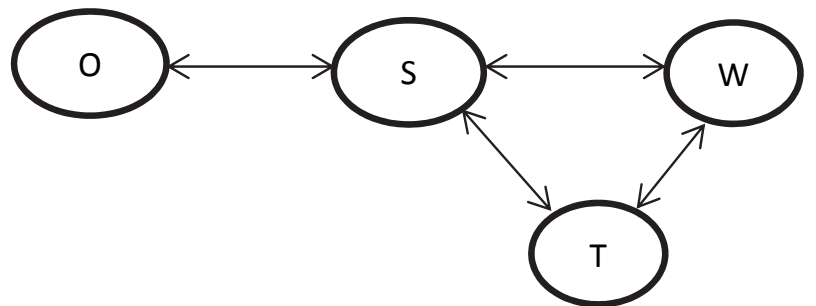

Fig. 3. Interdependencies between SWOT factors

The interdependency matrix tables of SWOT factors are as below:

Table 10

Interdependency matrix of SWOT factors given the strengths

\begin{tabular}{ccccc}
\hline & T & O & W & Relative weight \\
\hline W & 9 & $\frac{9}{4}$ & 1 & 0.643 \\
$\mathrm{~T}$ & 4 & 1 & $\frac{4}{9}$ & 0.286 \\
& 1 & $\frac{1}{4}$ & $\frac{1}{9}$ & 0.071 \\
\hline
\end{tabular}

$\mathrm{CR}=0.00$ 
Table 11

Interdependency matrix of SWOT factors given the weaknesses

\begin{tabular}{cccc}
\hline Relative weight & $\mathrm{T}$ & $\mathrm{S}$ & weaknesses \\
\hline 0.333 & $\frac{1}{2}$ & 1 & $\mathrm{~S}$ \\
0.667 & 1 & 2 & $\mathrm{~T}$ \\
\hline $\mathrm{CR}=0.00$ & & &
\end{tabular}

Table 12

Interdependency matrix of SWOT factors given the threats

\begin{tabular}{cccc}
\hline Relative weight & W & S & threats \\
0.125 & $\frac{1}{7}$ & 1 & $\mathrm{~S}$ \\
0.875 & 1 & 7 & $\mathrm{~W}$ \\
\hline
\end{tabular}

$\mathrm{CR}=0.00$

Once interdependency matrix of SWOT factors is obtained, the weight of interdependency of the main factors is earned after normalization via product of interdependency of the main factors (relative importance values obtained from the third phase) in the relative importance of relative factors of the main factors (Table 9). The weight of interdependency of the main factors is calculated as follows:

$\left[\begin{array}{cccc}1.000 & 0.333 & 1.000 & 0.125 \\ 0.643 & 1.000 & 0 & 0.875 \\ 0.286 & 0 & 1.000 & 0 \\ 0.071 & 0.667 & 0 & 1.000\end{array}\right] \times\left[\begin{array}{c}0.183 \\ 0.450 \\ 0.164 \\ 0.203\end{array}\right]=\left[\begin{array}{c}0.261 \\ 0.372 \\ 0.108 \\ 0.258\end{array}\right]$

As is observable, there is an obvious difference between the weight of obtained factors (table 9) and the weight of interdependency of factors. Now, given the weights obtained from ANP, the GRA is used for selection and ranking of companies. In this phase, we consider a matrix in which the four considered indicators are placed as the columns of the decision making matrix. Four types of designated strategies are counted also as the choices of matrix rows. Therefore, a matrix of $4 \times 4$ is made as below:

$\mathrm{D}=\left[\begin{array}{llll}{[0.06,0.17]} & {[0.13,0.24]} & {[0.27,0.43]} & {[0.35,0.49]} \\ {[0.06,0.18]} & {[0.15,0.24]} & {[0.10,0.22]} & {[0.23,0.35]} \\ {[0.21,0.34]} & {[0.21,0.35]} & {[0.12,0.24]} & {[0.09,0.19]} \\ {[0.42,0.55]} & {[0.29,0.43]} & {[0.25,0.37]} & {[0.09,0.21]}\end{array}\right]$

In order to evaluate the choices based on qualitative indicators, the grey numbers scale with collection of views of experts was used. To normalize the values of decision making matrix based on the indicators of strengths and opportunities which are qualitative and positive, the equation 1 was used, and equation 2 was employed also for indicators of weaknesses and threats which are qualitative and negative.

$$
\begin{array}{ll}
\otimes G_{I J}^{*}=\left[\frac{G_{i j}}{G_{j}^{\text {max }}}, \frac{\bar{G}_{i j}}{G_{j}^{\text {max }}}\right] \quad, G_{j}^{\max }=\max _{1 \leq i \leq m}\left\{\bar{G}_{i j}\right\}, \mathrm{j}=1,2, \ldots, \mathrm{k} \\
\otimes G_{I J}^{*}=\left[\frac{G_{j}^{\text {min }}}{\bar{G}_{i j}}, \frac{G_{j}^{\text {min }}}{\underline{G}_{i j}}\right] \quad, G_{j}^{\text {min }}=\min _{1 \leq i \leq m}\left\{\underline{G}_{i j}\right\}, \mathrm{j}=1,2, \ldots, \mathrm{k}
\end{array}
$$

Therefore, the normalized matrix is calculated as follows:

$$
\mathrm{D}^{*}=\left[\begin{array}{llll}
{[0.11,0.31]} & {[0.42,0.77]} & {[0.63,1.00]} & {[0.18,036]} \\
{[0.11,0.33]} & {[0.42,1.00]} & {[0.23,0.51]} & {[0.26,0.39]} \\
{[0.38,0.69]} & {[0.29,0.48]} & {[0.28,0.56]} & {[0.47,1.00]} \\
{[0.76,1.00]} & {[0.24,0.34]} & {[0.58,0.86]} & {[0.43,1.00]}
\end{array}\right]
$$


After calculation of the normalized matrix, the reference sequence is calculated by the equation below:

$$
A_{0}=\left\{\left[\max _{1 \leq i \leq m} \underline{G}_{i 1}^{*}, \max _{1 \leq i \leq m} \bar{G}_{i 1}^{*}\right], \ldots,\left[\max _{1 \leq i \leq m} \underline{G}_{i k}^{*}, \max _{1 \leq i \leq m} \bar{G}_{i k}^{*}\right], \max _{1 \leq i \leq m} R_{i, k+1}^{*}, \ldots, \max _{1 \leq i \leq m} R_{i n}^{*}\right\}
$$

The reference sequence obtained from the above equation is as:

$A_{0}=\{[0.763,1.00] \quad[0.416,1.00] \quad[0.628,1.00] \quad[0.473,1.00]\}$

Following calculation of the reference sequence and for the employed indicators based on the following equation, the Minkowski distance between each of the desired strategies (choices) and reference choice $\left(\mathrm{d}_{0 \mathrm{i}(\mathrm{j})}\right)$ is calculated:

$\mathrm{D}_{\mathrm{G}_{1 \mathrm{G}_{2}}}=\frac{1}{\sqrt[\mathrm{p}]{2}}\left[\left(\underline{\mathrm{G}}_{1}-\underline{\mathrm{G}}_{2}\right)^{\mathrm{P}}+\left(\overline{\mathrm{G}}_{1}-\overline{\mathrm{G}}_{2}\right)^{\mathrm{p}}\right]^{\frac{1}{\mathrm{p}}}$

The achieved results are as below:

$d_{0 i(j)}=\left|\begin{array}{llll}0.67 & 0.11 & 0.00 & 0.51 \\ 0.66 & 0.00 & 0.44 & 0.41 \\ 0.34 & 0.32 & 0.39 & 0.00 \\ 0.00 & 0.41 & 0.09 & 0.02\end{array}\right|$

As is observable in the above Minkowski distance matrix, the smallest entry is $\min _{i} \min _{j}\left\{d_{0 i(j)}\right\}=0$ and the largest is $\max _{i} \max _{j}\left\{d_{0 i(j)}\right\}=0.67$. Accordingly, the grey relative coefficient is calculated via the following equation:

$\boldsymbol{\xi}_{0 i(j)}=\frac{\min _{i} \min _{j}\left\{d_{0 i(j)}\right\}+\operatorname{pmax}_{i} \max _{j}\left\{d_{0 i(j)}\right\}}{d_{o i(j)}+\operatorname{pmax}_{i} \max _{j}\left\{d_{0 i(j)}\right\}} \quad 1 \leq i \leq m, 1 \leq j \leq n$

The grey relative coefficient between each choice and the reference sequence is calculated given the $j$ indicator:

$\boldsymbol{\xi}_{0 \mathrm{i}(\mathrm{j})}=\left|\begin{array}{cccc}0.33 & 0.75 & 1.00 & 0.39 \\ 0.33 & 1.00 & 0.43 & 0.44 \\ 0.49 & 0.51 & 0.46 & 1.00 \\ 1.00 & 0.44 & 0.78 & 0.94\end{array}\right|$

Considering the weights of interdependencies of the main factors that were calculated in the previous equations, the grey relationship between each strategy and the reference sequence is obtained via the equation below as:

$\gamma_{0 i}=\sum_{j=1}^{n} w_{j} \cdot \xi_{0 i(j)} \quad, \quad 1 \leq \mathrm{i} \leq \mathrm{m}$

where $w_{j}$ is the weight of standards in a way that $w_{j}>0$ and $\sum_{j=1}^{n} W_{j}=1$; the calculated values of grey relational point are:

$\gamma_{0 i}=\left|\begin{array}{l}0.573 \\ 0.617 \\ 0.623 \\ 0.750\end{array}\right|$

Given the calculated values, the greatest grey relational point belongs to WT strategies. These strategies, hence, are suggested as the best and most appropriate implementation choices in human resource system of APC. The next most suitable strategies are WO, ST, and SO. 


\section{Research conclusion and suggestions}

In the present era, the human resource management could not be considered a section dealing only with limited duties and responsibilities against employees. In change and competitive conditions, human resource management is in need of a comprehensive and strategic attitude to bring about competitive advantage and value added for organizations. The human resource strategic management, in line with the proposed needs, aims at providing companies with attaining the success (Ghasemi, 2003). In this connection, human resource strategy development has been set forth as a key factor which requires a systematic and all-inclusive approach to human resource strategic management (Azmi, 2008). Therefore, in current study and using PESTEL analysis, human resource excellence indicators together with SWOT analysis, internal factors (strengths and weaknesses), and external factors (opportunities and threats) of human resource management system of APC were identified within the three aforementioned processes and based on the presented analytical model, the appropriate human resource strategies were developed. Following adoption of appropriate strategies, the proposed strategies were evaluated and prioritized using ANP and GRA multi-criteria methods. Based on the achieved results, the organization is advised to take defensive strategy (WT) into consideration in its human resource process, followed by competitive strategies (ST), offensive (SO), and conservative (WO) as the next appropriate policies. This indicates that the organization is involved in inappropriate situation in terms of internal and external factors, i.e. the company faces with relative threats and relative weaknesses in terms of external and internal factors, respectively. This situation suggests that the company is expected to adopt defensive strategies, minimize weaknesses and avoid threats. If succeeding in implementation of the above proposed strategies would cause synergic activities and coordination between human resource policies and overall strategies in the organization. Innovative research, using ANP multicriteria technique and grey systems theory and quantitative data for ranking and considering more precise communications between the factors within human resource strategic management, as qualitative data, is considered a new approach in human resource strategic development. Ultimately, the followings are suggested to scholars for further research:

1. Investigation of coordination effect between human resource strategy, human capital, or organizational behavior and other strategies of the organization such as financial policies, and the relevant impact upon the performance of the company.

2. The present research could be used for investigation and identification of effective factors on human resource strategic management as well as formulation of human resource strategies in other Iranian organizations.

3. More dynamic strategies may be developed by employing the neural network in research.

4. Use of the research model for evaluation of the strategies of the organization in terms of each resource including train, selection and employment, rewards, compensation, etc.

\section{References}

Abaspour, A. (2009). Advanced Human Resource Management (approaches, process anf functions), Samt Pub, Tehran. [in Persian]

Abtahi, H., \& Sayedmousavi, M. (2009). Human Resource Strategies Development, Imam sadegh Human Resource Researches, 3, 1-23. [in Persian]

Ananthram, S., \& Chan, C. (2013). Challenges and strategies for global human resource executives: Perspectives from Canada and the United States. European Management Journal, 31(3), 223-233.

Azmi, F. T. (2010). Strategic human resource management: scale development and validation. Philippine Management Review, 17.

Bamberger, P., \& Meshoulam, I. (2000). Human resource strategy: Formation, implementation, and impact. Thousand Oaks, CA: Sage Publications, Inc.

Buller, P. F. \& McEvoy, G. M. (2012). Strategy, human resource management and performance: Sharpening line of sight. Human Resource Management Review, 22(1), 43-56.

Chadwick, C., \& Cappelli, P. (1999). Alternatives to generic strategy typologies in strategic human resource management. Research in Personnel and Human Resources Management, Supplement, 4, 11-29 
Delery, J. E., \& Shaw, J. D. (2001). The strategic management of people in work organizations: Review, synthesis, and extension.

Dincer, O. (2004). Strategy Management and Organization Policy. Istanbul: Beta Publication.

Farahi, M. (2007). Impact of human resource and organizational strategies alignment on organizational performance, M.S Dissertation in the field of HRM, Faculty of management of university of Tehran. [in Persian]

Ferris, G. R., Arthur, M. M., Berkson, H. M., Kaplan, D. M., Harrell-Cook, G., \& Frink, D. D. (1998). Toward a social context theory of the human resource management-organization effectiveness relationship. Human Resource Management Review, 8(3), 235-264

Ghasemi, M.(2003). Strategic Human Resource Management. Management Development Journal, 51, 32-51. [in Persian]

Hill, T. \& Westbrook, R. (1997). SWOT analysis: it's time for a product recall.Long range planning, 30(1), 4652.

Hsu, C. I., \& Wen, Y. H. (2000). Application of grey theory and multiobjective programming towards airline network design. European Journal of Operational Research, 127(1), 44-68.

Jazani, N. (2002). Human Resource Strategies Development. Bureaucratic Transformation Journal, 7(41), 31 44. [in Persian]

Julong, D. (1989). Introduction to grey system theory. The Journal of grey system, 1(1), 1-24.

Khaef elahi, A., \& Babashahi, J. (2011). Make or Buy; Human resource Problems. Imam HosseinHuman Resource Research Journal, 1, 75-92. [in Persian]

Kurttila, M., Pesonen, M., Kangas, J., Kajanus, M. (2000). Utilizing the analytic hierarchy process (AHP) in SWOT analysis-a hybrid method and its application to a forest-certification case. Forest Policy and Economics, 1, 41-52.

Li, G. D., Yamaguchi, D., \& Nagai, M. (2007). A grey-based decision-making approach to the supplier selection problem. Mathematical and Computer Modelling, 46(3), 573-581.

Momeni, M., Safari, M., Maleki, M., \&Hassan, M.(2012). Organizational strategy development by SWOT-ANP, $4^{\text {th }}$ international strategic management conference, Tehran. [in Persian]

Rayej, H., Sayedjavadin, S., \& Sharifi, S. (2009). Role Human resource in achieving Iran 1404 visions in the field of oil industries, Human resource management journal in oil industries, 6, 88-101. [in Persian]

Rostami, A., \& Jazani, N. (2011). Design and developing knowledge base human resource empowerment model, Organizational Resource Research Journal, 3, 23-53. [in Persian]

Saaty, T. L. (1980). The analytic hierarchy process: planning, priority setting, resources allocation. New York: McGraw.

Saaty, T. L. (2006). The Analytic Network Process (pp. 1-26). Springer US.

Sayadi, S., \& Mohammadi, M. (2009). Theoretical perspective of strategic human resource. Bahar Researchers, 13, 43-51. [in Persian]

Stewart, G. L., \& Brown, K. G. (2010). Human resource management. Wiley Global Education.

Stewart, R., Mohamed, S. \& Daet, R. (2002). Strategic Implementation of IT/IS Projects in Construction: A Case Study. Automation in Construction, 11, 681-694.

Tyson, S. (1987). The management of the personnel functions. Journal of Management Studies, 24(5), 523-532.

Wright, P. M., \& McMahan, G. C. (1992). Theoretical perspectives for strategic human resource management. Journal of management, 18(2), 295-320.

Wright, P. M., \& Sherman, W. S. (1999). Failing to find fit in strategic human resource management: Theoretical and empirical problems. Research in Personnel and Human Resources Management, 4, 53-74.

Yuksel, E., Dagdeviren, M. (2007). Using the analytic network process in a SWOT analysis: A case study for a textile firm. Information Science, 177, 3364-3382.

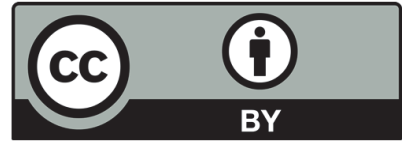

(C) 2016 by the authors; licensee Growing Science, Canada. This is an open access article distributed under the terms and conditions of the Creative Commons Attribution (CC-BY) license (http://creativecommons.org/licenses/by/4.0/). 